\title{
POLÍTICA EXTERIOR DA ARGENTINA E ESCOLHA INSTITUCIONAL: A OEA NO ESPELHO DA UNASUL E DO MERCOSUL*
}

Federico Merke

Quando dois ou mais Estados decidem cooperar com a provisão de um bem público regional, uma das primeiras decisões a ser adotada, consiste em definir se a cooperação terá um caráter fortuito, ad-hoc, ou se será permanente, através de canais institucionais. Se a cooperação for institucionalizada, a segunda questão será a seleção institucional, ou seja; qual será a instituição que utilizarão para a provisão do bem público (Jupille e Snidal, 2005). São várias as opções. Os Estados podem utilizar uma instituição por ser a mais conhecida e mais eficiente. Também podem selecionar uma instituição no catálogo de instituições, dentre aquelas que estão concorrendo entre si. Se as instituições que estão no catálogo não são satisfatórias, os Estados podem modificar

\footnotetext{
* Este trabalho não seria possível sem a colaboração de Silvana Elizondo, Soledad Altrudi e Luciana Ramírez, que me assistiram eficientemente em sua pesquisa. O texto foi enriquecido pelas discussões e intercâmbios realizados no marco do Projeto de Investigação sobre o Sistema Interamericano de Defesa, financiado pelo Ministério de Defesa da Argentina. Agradeço em particular a Ricardo Alessandrini, Silvana Elizondo, Virginia Iribarne e Silvana Pascucci, pesquisadores do projeto. Agradeço também os comentários de Gino Pauselli.
} 
alguma das já existentes, para adaptá-la às novas necessidades. Se nenhuma dessas opções for possível, os Estados podem criar uma nova instituição.

Desde 1983, a Argentina adotou um perfil elevado na provisão de três bens públicos regionais: segurança interestatal, democracia e direitos humanos. Entre 1983 e 2001, a escolha institucional da Argentina consistiu em utilizar a Organização dos Estados Americanos (OEA) para fortalecer os três bens públicos. O primeiro, e mais antigo, foi o regime de segurança, articulado em torno do Tratado Interamericano de Assistência Recíproca (TIAR), da Carta da OEA, da Junta Interamericana de Defesa (JID) e do Pacto de Bogotá. O segundo bem público foi o regime dos direitos humanos. Constituído a partir da Declaração dos Direitos Humanos (que inspirou a criação da Comissão Interamericana de Direitos Humanos) e da Convenção (que criou a Corte Interamericana de Direitos Humanos). O terceiro, e mais 66 recente, foi o bem desenhado para defender a democracia, articulado em torno da Carta da OEA, da Resolução 1.080 e da Carta Democrática.

Contudo, a partir de 2001, a escolha institucional da Argentina consistiu em uma combinação de uso, seleção, modificação e criação. Por um lado, a Argentina questionou os instrumentos de segurança hemisférica e buscou modificá-los para reduzir sua importância, investindo tempo e recursos na criação de uma instituição sul-americana, o Conselho de Defesa Sul-Americano da União das Nações Sul-Americanas (Unasul). Por outro lado, a Argentina deixou de usar exclusivamente as normas da OEA para defender a democracia e começou a selecionar normas de um catálogo estabelecido pela OEA, pelo Mercosul e pela Unasul, convocando diversas instituições em diferentes momentos. Finalmente, a Argentina continuou utilizando os acordos institucionais da OEA para promover e defender os direitos humanos. Em síntese, a Argentina fez diversas escolhas ins- 
titucionais dependendo do bem público em questão. O país vem contribuindo com a criação institucional para cooperar com a segurança, com a seleção institucional para promover a democracia e com o uso institucional para promover os direitos humanos.

Que fatores explicariam essa variação na escolha institucional da Argentina? Este trabalho examina as escolhas institucionais do país para a provisão de três bens públicos regionais: segurança interestatal, democracia e direitos humanos. O estudo se concentra na escolha institucional recente (de 2003 em diante) e a contrasta com o passado imediato (década de 1990) e o mais distante (desde a criação da OEA), para identificar as mudanças e continuidades.

O texto é dividido em duas partes. A primeira examina a escolha institucional a partir da teoria das relações internacionais e fornece um modelo analítico. A segunda parte explora a variação de escolha institucional em cada um dos bens públicos regionais estudados. Por fim, a conclusão traz observações finais para a Argentina e considerações conceituais para a compreensão dos determinantes da escolha institucional.

\section{Determinantes da escolha institucional}

A variável dependente deste trabalho é a escolha institucional da Argentina. A escolha institucional consiste na decisão que os governos fazem sobre qual instituição irão utilizar, abrangendo a criação de instituições, sua seleção e possível modificação. Esse parâmetro representa as opções institucionais que possuem os Estados no momento de cooperação. A Figura 1 (Jupille e Snidal, 2005, p.15) representa as opções institucionais que possuem os Estados no momento de cooperação.

$\mathrm{O}$ que determina a escolha institucional? Existem ao menos duas formas para responder a essa pergunta. A primeira sugere que aquilo que determina a escolha ins- 


\section{Figura 1}

Opções Institucionais

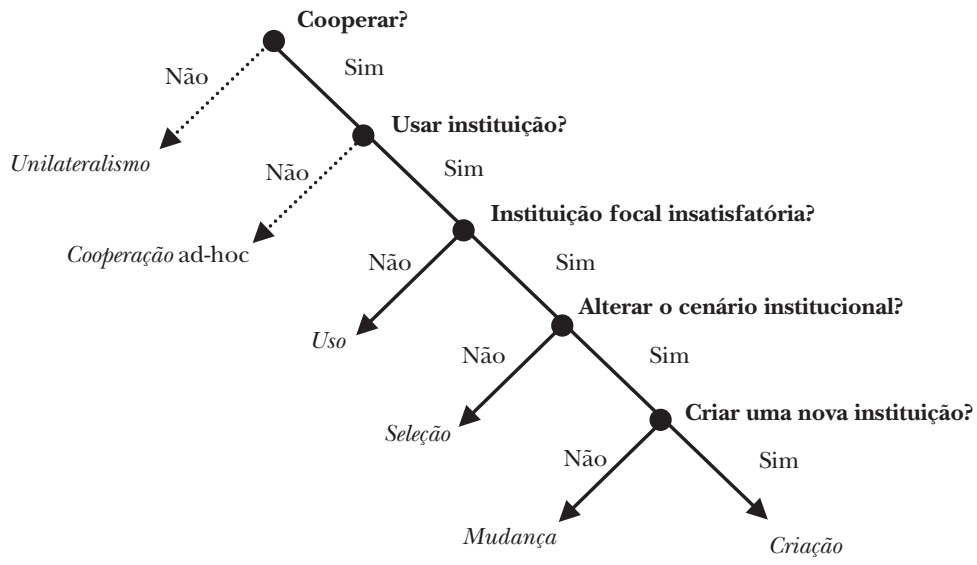

68 titucional relaciona-se com a natureza do sistema internacional. Para o realista, a chave está na distribuição de poder, mas, para o institucionalista, está no nível da institucionalização. A segunda sugere que o que determina a escolha institucional está associado à natureza das preferências domésticas. Vamos analisar as duas teorias sistêmicas e, em seguida, a teoria das preferências domésticas.

A escolha institucional é um problema pouco estudado pela perspectiva realista, simplesmente porque o realismo considera que as instituições internacionais "são basicamente um reflexo da distribuição do poder mundial" (Mearsheimer, 1994-95, p.7). Tipicamente no raciocínio realista essa perspectiva "sai" pela diagonal nas primeiras bifurcações entre cooperar (multilateralmente) e não cooperar (unilateralmente), entre cooperar de maneira aleatória ou institucionalizada. Se, no raciocínio realista, desliza-se "em descendente" pela diagonal, a predição realista sustenta que os Estados mais poderosos desenharão as instituições que melhor maximizarem suas utilidades. Esta é a ideia central da teo- 
ria de estabilidade hegemônica. Em particular, a teoria sustenta que são os Estados com maior poder relativo que oferecem instituições como forma de atenuar os problemas de ação coletiva, garantir a estabilidade, incluir potenciais adversários e socializar suas preferências.

No entanto, a teoria de estabilidade hegemônica não elabora as possíveis respostas dos Estados menores. Supõe, em todo caso, que esses Estados aceitarão a oferta dos mais poderosos, porque a estabilidade hegemônica é preferível à ausência de coordenação, que conduz a equilíbrios instáveis. Com este raciocínio, os Estados que aceitarem a oferta do Estado hegemônico farão uso das instituições oferecidas. Se continuarem com esse pensamento, será possível afirmar que, à medida que aumenta a rejeição à oferta institucional do Estado hegemônico, a escolha institucional resultará no extremo da modificação e da mudança. Em termos mais gerais, poderíamos dizer que a escolha institucional será uma função da meta procurada pela política externa, que poderá ir desde o equilíbrio até o alinhamento.

A segunda explicação sistêmica, institucionalista, sustenta que os determinantes da escolha institucional relacionam-se com a natureza do problema de cooperação e com o status quo institucional (Jupille e Snidal, 2005). Basicamente, o problema da cooperação pode ser associado com o número de atores envolvidos, o horizonte temporal que dispõem e os interesses em jogo de cada ator. O status quo institucional refere-se à passagem institucional preexistente à aparição do problema. Se, no momento de aparecer o problema, existe uma instituição focal, é possível que os Estados façam uso dela ${ }^{1}$. Este é o cenário pensado pelo institucionalismo liberal, no qual instituições fortes dão

\footnotetext{
${ }^{1}$ Usar uma instituição já conhecida e aceita implica um baixo nível de custos de transação e um baixo nível de incerteza. Uma instituição é focal quando provê uma solução relativamente satisfatória ao problema de cooperação. Nessa circunstância, a paisagem institucional não é problematizada, mas tomada como algo dado.
} 
forma ao comportamento dos Estados (Keohane, 1993). Se existem duas ou mais instituições focais em competição, os Estados tentarão selecionar a que melhor lhes convier, praticando o que se denomina forum shopping (Hofmann e Mérand, 2012) ${ }^{2}$. Quando não existir uma instituição focal, nem instituições alternativas, os Estados modificarão uma instituição parar abordar os novos problemas de cooperação ${ }^{3}$. Finalmente, se não existir uma instituição focal, nem um catálogo de instituições para selecionar, nem outra para modificar, a conclusão lógica é que, para cooperar de maneira institucionalizada, os Estados devem criar uma nova instituição ${ }^{4}$.

Tanto o realismo, como o institucionalismo oferecem importantes aportes para compreender a escolha institucional da Argentina na cooperação regional pela segurança, pelos direitos humanos e pela democracia. Durante os anos 1990, um dos espaços por meio do qual a Argentina buscou 70 expandir seus caminhos com os Estados Unidos foi precisamente a OEA e seus discursos sobre segurança, direitos humanos e democracia. O alinhamento e o uso da OEA caminharam de mãos dadas. Mais tarde, entretanto, em 11 de Setembro, as mudanças domésticas na Argentina precipitaram outro rumo. O país começou a se distanciar da OEA quando os Estados Unidos passaram a ser vistos como

\footnotetext{
${ }^{2}$ Nessas circunstâncias, é provável que diferentes organizações internacionais concorram para resolver o problema de cooperação. O problema da seleção surge quando aumentam os revezes de distribuição. Surge, também, quando existem mais interesses em jogo. Nesse contexto, os Estados buscarão solucionar o problema com a instituição de maior conveniência.

${ }^{3}$ Em processos de mudança institucional, os interesses serão maiores. Também se elevarão os custos de transição e a incerteza, o que significa que a mudança é mais provável quando os horizontes temporais são mais amplos. Por último, as mudanças podem implicar maiores gastos (de funcionários, de logística, de infraestrutura etc.), o que sugere que ela é mais provável quando um ou mais Estados poderosos estão dispostos a pagar mais que os demais.

${ }^{4}$ Dado que o custo, o risco e a incerteza aumentam à medida que nos movemos "para baixo" da diagonal, se os atores têm aversão ao risco, então prevalecerão o uso e a seleção sobre a mudança e a criação.
} 
um ator unilateral e imperial e quando a relativa queda do domínio e da influência estadunidenses demarcou um período de transição para um esquema mundial multipolar. Como resultado, a Argentina propôs realizar uma revisão, para modificar as atribuições e funções do sistema interamericano de defesa. Trabalhou também, junto ao Brasil, na criação de uma instituição sul-americana de defesa. Em síntese, à medida que a Argentina se moveu do alinhamento ao equilíbrio, também deslizou "para baixo", indo do uso à criação. Sob o olhar realista, a escolha institucional da OEA, pela Argentina, parece ter sido uma função de sua orientação aos Estados Unidos.

Com base em um enfoque institucionalista, nos anos 1990, pareceu estar claro que a OEA era uma instituição focal na qual predominava o consenso sobre a democracia e a segurança cooperativa. A Argentina avançou com passo firme na mesma direção. Hoje, a OEA parece estar sobrecarregada de assuntos a serem discutidos e vivenciando a queda substancial de recursos materiais e simbólicos para enfrentá-los. Observa-se, assim, uma heterogeneidade maior de preferências estatais, em que a democracia, os direitos humanos e a segurança são valores objetados e discutidos pelos principais sócios da organização. A OEA parece haver experimentado um ciclo de maior legitimidade durante os anos 1990 e um ciclo de declínio nos últimos anos, deixando de ser uma instituição focal para ser uma instituição que compete com outras organizações regionais de menor alcance, caso da Unasul. As propriedades do problema de cooperação também parecem ter se modificado, passando de um cenário de atores com preferências convergentes (nos anos 1990) para um cenário marcado por maior grau de heterogeneidade nas preferências. A orientação da Argentina parece haver adotado esse caminho, a partir do momento em que ocorreu seu deslizamento do uso "para baixo" da diagonal. 
Ambos os enfoques apontam elementos importantes para explicar a escolha institucional, e a combinação deles pode ser mais útil do que se fossem tratados como hipóteses mutuamente excludentes. Mas os dois apresentam um problema similar, que se relaciona com a inconsistência da política exterior argentina. Tanto o realismo estrutural como o institucionalismo sustentam que o Estado é o ator principal da política internacional, definindo suas metas de maneira racional e coerente. Isso significa que os Estados estabelecem preferências de modo transitivo (por exemplo, não poderiam escolher a criação como primeira opção e o uso como segunda), e que essas preferências se transformam em estratégias consistentes (por exemplo, não buscariam ao mesmo tempo o uso e a criação institucional).

Se atentarmos para a política exterior da Argentina direcionada à OEA, veremos inconsistência na escolha ins72 titucional, e, ao mesmo tempo, preferência ao uso (direitos humanos), à seleção (democracia) e à modificação/ criação (segurança). Se o realismo argumenta que o alinhamento ou o equilíbrio são levados a cabo pelo Estado em seu conjunto, o caso argentino mostra instância de alinhamento (direitos humanos) e oscilação (segurança) nos extremos, reservando à democracia um lugar intermediário entre ambas as estratégias. Algo similar ocorre com a explicação institucionalista, que dá conta da tendência geral (do uso à criação), mas não o faz quando se pensa nas variações entre temas dentro de uma mesma organização. Em matéria de direitos humanos, por exemplo, a OEA continua sendo a instituição principal para a Argentina. Já a Carta Democrática permanece no "catálogo" normativo da Argentina, mesmo que em competição (não necessariamente em conflito) com o Protocolo Adicional da Unasul e com o Protocolo de Ushuaia, do Mercosul. Finalmente, o sistema interamericano de segurança é fortemente cri- 
ticado pela Argentina, que busca reformá-lo ou simplesmente deixá-lo morrer.

Para corrigir esse problema, é preciso recorrer à segunda forma de analisar a escolha institucional e pensar na natureza das preferências domésticas. O enfoque doméstico liberal afirma que a relação entre o Estado e a sociedade é um fator central que configura a ação externa dos Estados. Enquanto o realismo estrutural considera a distribuição de capacidades e o institucionalismo analisa a distribuição da informação, o enfoque liberal doméstico sustenta que as preferências são analiticamente prévias às capacidades e à informação, e, portanto, ajudam a definir as condições em que os supostos institucionalistas e realistas se sustentam (Moravcsik, 1997). Uma vez que identifica os atores domésticos mais importantes e suas preferências, o enfoque liberal considera de que modo essas preferências convergem nos níveis mais altos de decisão. O resultado, então, é que não existe, como acreditam os realistas, um Estado racional e unitário que conhece objetivamente seu interesse nacional. O que existe é um Estado que representa algum conjunto da sociedade, e que nem sempre terá a capacidade de agregar preferências de maneira consistente.

A partir de um enfoque inspirado no ecletismo analítico (Katzenstein e Sil, 2010), o trabalho analisa a escolha institucional da Argentina para cooperar em segurança, democracia e direitos humanos. Para isso, considera a natureza do poder e as instituições vinculadas a cada um desses três bens públicos. A seguir, analisa as preferências domésticas para cada bem. Por questões de espaço, este artigo apresenta esses dois níveis de análise de maneira sucinta, buscando apenas mostrar como o poder e as instituições interagem com as preferências da Argentina. 


\section{0 regime interamericano de segurança e a escolha institucional da Argentina}

$\mathrm{O}$ regime interamericano de segurança foi essencialmente uma construção hegemônica oferecida pelos Estados Unidos, que trabalhou sob os pressupostos da teoria de estabilidade hegemônica. Primeiro, mesmo que os players fossem muitos, a hegemonia desse país serviu para garantir a segurança e pressionar os Estados da região a aceitar sua oferta institucional. Segundo, as perspectivas de cooperação, com o tempo, tornaram-se sólidas em um hemisfério bastante alienado, mas alinhado aos Estados Unidos com seus valores e visões de mundo. Terceiro, a vinculação temática e a capacidade de pagamentos laterais por esse país aumentaram as possibilidades de cooperação. Muitos Estados viram nos Estados Unidos um potencial provedor de crédito, de ajuda, de segurança e de armas, com isso, o TIAR foi considerado uma peça a mais de barganha bilateral. Quarto, a 74 informação foi fluida em seus começos através da OEA e da JID, ajudando a atenuar a surpresa militar.

A garantia de segurança se estruturou em torno da Junta Interamericana de Defesa (criada em 1942) e do TIAR (firmado em 1947), continuando com o estabelecimento da OEA (em 1948) e, posteriormente, com o Colégio Interamericano de Defesa (CID) (em 1962). Os Estados Unidos pagaram por essas iniciativas e a OEA foi a instituição focal que procurou articular, nem sempre com êxito, as diferentes peças institucionais e jurídicas. Durante boa parte da Guerra Fria, o nível de convergência nas preferências foi substantivo, e a lógica do regime foi essencialmente da segurança coletiva. A União Soviética (como poder) e o comunismo (como ideia) foram definidos como a principal ameaça à região e estruturaram boa parte dos conflitos entre e dentro dos Estados locais.

Terminada a Guerra Fria, a sensação de ameaça compartilhada foi decrescendo. As preferências em torno das defi- 
nições de defesa e segurança e das forças armadas tornaram-se cada vez mais divergentes. A segurança coletiva foi dando lugar à segurança cooperativa, mais concentrada na prevenção e construção de confiança, que na reação conjunta perante ameaças externas. Paralelamente a essa prática westfaliana, surgiu uma lista de novas ameaças "pós-westfalianas", como o narcotráfico, o terrorismo e o crime organizado.

Após o 11 de Setembro, as duas opções temáticas - antigos e novos temas de segurança - foram se fundindo em uma opção mais ampla. A heterogeneidade de preferências vem dominando, desde então, os debates hemisféricos, e a existência de muitos players no hemisfério já não é tão debilitada pela hegemonia dos Estados Unidos, que está em um de seus pontos mais baixos de sua história nas Américas. $\mathrm{O}$ país não parece disposto a pagar por maior cooperação institucionalizada, como fez em 1945. A crise de orçamento da OEA e da JID são um indício desse fato. Quanto à perspectiva temporal, os Estados da região parecem ter assumido que haverá uma queda (mesmo que lenta) dos Estados Unidos e apostado na ascendência do Sul Global, composto de múltiplas alianças. Nem a vinculação temática parece oferecer muitos incentivos de cooperação, sob a ameaça de que não cooperar em um tema tenha custos na cooperação em outros.

O fim da Guerra Fria e o regresso da democracia, de um lado, e as divergências entre Estados Unidos e América Latina, de outro, fizeram o regime de segurança cair em desuso. Hoje, o TIAR não goza de legitimidade e é pouco utilizado. A JID é pouco operativa e enfrenta sérias restrições de orçamento, possui poucos funcionários e é pouco demandada. Trata-se de um regime de segurança que, no início, demonstrou ter capacidade para alterar a conduta dos Estados, em particular quando o TIAR foi invocado, mas, hoje, seu nível de institucionalização está no ponto mais baixo e faz tempo que deixou de ser uma instituição focal. Isso não significa ausência de conflitos e de interes- 
se sobre como viabilizar essas instituições. Significa que o contexto atual combina baixo nível de institucionalização com alto nível de heterogeneidade nas preferências, o que dificulta uma revisão substantiva do regime.

Diante de um regime hemisférico em declínio, a América do Sul experimenta a ascensão de um fórum regional, a Unasul, que contempla entre suas tarefas a cooperação de seus membros no campo de defesa. Com efeito, uma das agências que mostrou vitalidade desde o começo foi o Conselho de Defesa Sul-Americano (CDS). Entretanto, essa situação convive com outra: trata-se de uma divergência de orientações entre os Estados da região. Alguns países, como a Colômbia, por exemplo, põe o foco de seu interesse na segurança e consideram que os Estados Unidos podem cooperar para provê-la. Outros, como Venezuela e Bolívia, têm mais interesse na soberania e na defesa do regime político vigente em seu país e consideram que os Estados Unidos são a principal ameaça.

76 Outros ainda, como a Argentina, priorizam a autonomia e preferem se manter distantes dos Estados Unidos e reduzir as probabilidades de que este atue de maneira unilateral. E finalmente o Brasil prefere investir na projeção regional e global e considera a autonomia tão importante como a cooperação entre países de maior poder relativo, aqueles que, no final, irão lhe conceder maior legitimidade internacional.

\section{As preferências argentinas}

A orientação da Argentina no que diz respeito ao regime de segurança da América do Sul esteve pautada por uma preferência que se manteve relativamente estável ao longo de diferentes governos: não aceitar respostas operativas que envolvam ações comuns no plano militar. Com o regresso da democracia, em 1983, uma segunda preferência, compartilhada por governos radicais e peronistas, dominou a orientação do país: não aceitar princípios normativos nem regras operativas que reduzissem a separação entre defesa 
e segurança. Finalmente, uma terceira preferência consistiu em utilizar a OEA como fórum relevante para expor a defesa da soberania sobre as ilhas Malvinas. De fato, a Argentina usou o TIAR em duas ocasiões, a primeira em 1982 durante o conflito com o Reino Unido e a segunda em 2001 perante o ataque das torres gêmeas em 11 de Setembro.

Com o fim da Guerra Fria, a Argentina promoveu, de maneira sensível, a discussão sobre segurança no contexto da OEA e apoiou, com entusiasmo, a segurança cooperativa, uma forma de pensar a segurança que envolve o diálogo e a cooperação entre Estados através da consulta e do fortalecimento da confiança. O país também aderiu aos princípios do controle civil das forças armadas e da transparência do gasto militar. $\mathrm{O}$ alinhamento com os Estados Unidos veio de mãos dadas com o uso da OEA para os assuntos de segurança.

O 11 de Setembro, a perda de poder relativo da OEA e a instauração de uma nova aliança política na Argentina, a partir de 2003, fizeram com que o país deixasse de usar a OEA e começasse a criticar a organização, que passou a ser vista como muito controlada pelos Estados Unidos, ao menos no plano da segurança. A partir de 2003, a Argentina se aliou ao grupo Aladi para promover uma JID não operativa, e, anos mais tarde, deixou de enviar estudantes ao Colégio Interamericano. Em 2010, na Cúpula de Ministros da Defesa das Américas, realizada em Santa Cruz de la Sierra, o país propôs revisar a missão e os instrumentos do sistema interamericano de defesa. Em março de 2012, a representação permanente na OEA apresentou um documento com críticas à JID, afirmando que a organização avança em tarefas que não lhe foram delegadas e questionando a liderança canadense por dirigir as ações da JID às preferências do Canadá e dos Estados Unidos ${ }^{5}$.

\footnotetext{
${ }^{5} \mathrm{O}$ documento sustentou que a JID "gasta recursos humanos e financeiros que não redundam em benefícios reais e efetivos [...] para a realidade interamericana" (Argentina, 2012).
} 
Houve um olhar crítico ao TIAR, que, nas palavras de Jorge Arguello, embaixador nas Nações Unidas entre 2007 e 2011: "ficou sepultada no Atlântico Sul". Em abril de 2012, o então vice-ministro de Defesa, Alfredo Forti, se referiu ao "anacronismo da instituição militar continental" que "ainda hoje não reflete, em nível interamericano, o esquema próprio de um Estado de direito" (Forti, 2012). Durante o primeiro mandato de Cristina Kirchner, e a seu pedido, o Grupo Militar (uma representação do Comando Sul na Argentina), teve de deixar seus escritórios localizados no Edifício do Estado Maior. O governo limitou o contato direto desse grupo com as forças armadas do país e retirou o apoio militar argentino do Comando Sul e da Joint Interagency Task Force South, localizada na Flórida. Dispôs-se ainda a não enviar apoio à Quarta Frota, com sede em Mayport, também na Flórida. Finalmente, a Argentina retirou o representante do Ministério de Defesa na JID, que hoje é 78 atendido pelo adido militar na Embaixada Argentina em Washington (Verbitsky, 2012).

O distanciamento do país das instituições da defesa da OEA se contrapõe à sua aproximação da proposta brasileira de criar um Conselho de Defesa Sul-Americano da Unasul. A Argentina tem sido um dos Estados mais ativos da região para sua promoção e consolidação como um espaço de cooperação. É a sede do Centro de Estudos Estratégicos desse Conselho, e um ponto focal para a discussão de suas atividades.

Essa movimentação relaciona-se, em parte, com a perda do espaço da chancelaria no manejo da relação com a OEA em matéria de defesa e segurança (a Argentina, por exemplo, não contava com embaixador na OEA entre 2010 e 2013) e com uma maior presença do Ministério de Defesa. Esse ministério participa das reuniões da CSH por meio de seu attaché em Washington. Também tem um papel importante na relação com a Junta Interamericana de Defesa e o Colégio Interamericano de Defesa, âmbitos pouco visitados 
pelos diplomatas sediados na representação em Washington. E, ainda, a defesa tem um papel central na Conferência de Ministros de Defesa das Américas, fórum especial onde se discutem a agenda do regime interamericano.

\section{Da modificação da OEA à criação do CSD}

A escolha institucional da Argentina parece determinada por uma combinação de fatores sistêmicos e domésticos. A OEA deixou de ser uma instituição focal para a condução da segurança, o que incentiva a Argentina a procurar modificar o Sistema Interamericano de Defesa, por um lado, e criar instituições sul-americanas, por outro. Apesar da tentativa dos Estados Unidos para fortalecer o regime hemisférico, não está claro quão disposto esse país estava para encarar o papel de estabilizador hegemônico. A Argentina, entretanto, rejeita as preferências estadunidenses, e essa rejeição parece surgir nas preferências domésticas dos atores mais envolvidos na discussão pela defesa e segurança. Finalmente, a existência da uma alternativa como a Unasul, e seu Conselho de Defesa Sul-Americano, reforça a preferência por um baixo investimento no nível da OEA e abre a possibilidade de pensar a defesa regional em termos subsidiários, isto é, não fazer em nível hemisférico o que pode ser feito em nível regional. Em resumo, não existe hoje na Argentina, uma aliança de atores interessados em fortalecer o regime interamericano. A preferência dominante tem seu ponto focal, além da Presidência, no Ministério de Defesa, e, até o momento, a chancelaria não tem capacidade de veto.

\section{0 regime interamericano de democracia e a escolha institucional da Argentina}

Diferentemente de sua ação no regime de segurança, os Estados Unidos não foram um provedor da democracia na região. Os governos anticomunistas, mesmo que autoritários, foram preferidos aos governos de esquerda, mes- 
mo que democráticos. O fim da Guerra Fria alterou essa lógica e os Estados Unidos utilizaram o momento para fortalecer a democracia. Assim, o regime democrático está em construção desde os anos 1990. Mesmo que relativamente jovem comparado com o regime de defesa, sua evolução tem sido intensa e hoje a região conta com uma grande quantidade de normas hemisféricas e regionais que protegem a democracia como bem público regional. Lautaro Ramírez (2011) identifica dezessete instrumentos internacionais (entre declarações e tratados) que protegem os sistemas democráticos nas Américas, sete da OEA, quatro do Mercosul e seis da Unasul. Desses dezessete, três são peças centrais para a América do Sul: o Protocolo de Ushuaia, do Mercosul (de 1998), a Carta Democrática Interamericana (de 2001) e o Protocolo Adicional da Unasul (de 2010).

A Carta Democrática Interamericana é atualmente a 80 peça central do regime. De acordo com o Comitê Jurídico Interamericano, o objetivo central da Carta foi "atualizar, interpretar e aplicar a Carta fundamental da OEA em matéria de democracia representativa", apontando um "desenvolvimento progressivo do direito internacional" (CJI/RES 159 LXXV-O/09). Sua existência relaciona-se com duas situações: por um lado, os governos fortaleceram o compromisso com a democracia por temer uma regressão autoritária; por outro, optaram pela Carta como forma de aumentar a credibilidade de suas políticas públicas.

A Carta foi invocada a primeira vez em 2002 quando o presidente Hugo Chávez, da Venezuela, sofreu um golpe de Estado. A OEA condenou o golpe e ajudou na medição entre governo e oposição. Em doze anos de existência, a Carta auxiliou a atuação prévia da OEA em ao menos sete situações: em 2002, na Venezuela; em 2005, na Nicarágua; em 2005 e 2010, no Equador; em 2008, na Bolívia; em 2009, na Guatemala; e, em 2010, no Haiti. 
Apesar de a Carta Democrática ser um ponto focal, não é o único para a América do Sul. O Mercosul e a Unasul se converteram também em pontos focais; por isso, a paisagem institucional oferece um "catálogo" de instituições competindo para resolver crises democráticas. Além disso, as normas da Unasul e do Mercosul parecem ter assumido maior sentido nos últimos anos e foram utilizadas nos conflitos ocorridos na Bolívia em 2008, no Equador em 2010 e no Paraguai em 2011 ${ }^{6}$. A percepção que domina vários países da região é que o compromisso da Carta Interamericana parece estar sujeito aos interesses dos Estados Unidos. A crise democrática em Honduras deixou vislumbrar que os Estados Unidos optaram pela estabilidade do regime antes da democracia. Honduras dividiu de algum modo a região, com uma América do Sul menos inclinada a negociar com o presidente de fato, e uma América do Norte mais pragmática em seu enfoque de conflito.

Mesmo que a preferência geral das elites políticas argentinas pela democracia tenha sido estável e venha crescendo desde 1983, as posições argentinas diante de diversas crises democráticas foram evoluindo em dois sentidos. Por um lado, a Argentina mostra, desde os anos 1990 até então, um endurecimento de suas posturas perante as crises democráticas. Por outro lado, mostra distintos graus de investimento institucional, aumentando sua ação no fortalecimento democrático no Mercosul e na Unasul, e mantendo seu compromisso na OEA. Nesse sentido, a escolha institucional da Argentina se aproxima da seleção.

O endurecimento da posição argentina se manifesta ao comparar a postura benigna adotada diante do assassinato, em março de 1999, de Luis Maria Argaña, vice-presi-

\footnotetext{
${ }^{6}$ É pelo menos curioso observar que a Decisión 26/2012 da Unasul, que suspendeu o Paraguai da entidade, em junho daquele ano, invocou os compromissos da Unasul, do Mercosul e da Celac com os princípios democráticos, omitindo, porém, a Carta Interamericana, subscrita pelo Paraguai.
} 
dente do Paraguai, e da denúncia de fraude feita por Alejandro Toledo contra o então presidente do Peru, Alberto Fujimori. Logo após a Carta e a crise institucional que a Argentina viveu no fim de 2001 e começo de 2002, as posturas se tornaram mais firmes. Em 2003, a crise na Bolívia, que resultou na renúncia do presidente Gonzalo Sanchez de Lozada e na assunção de Carlos Mesa foi um ponto de inflexão. A Argentina foi mais longe do que a posição fixada pela OEA (chamar ao diálogo, primeiro, e, depois, parabenizar pela sucessão constitucional) e decidiu enviar um representante da chancelaria, Eduardo Sguiglia, que afirmou que a missão da Argentina era "ajudar a garantir a continuidade institucional”. Essa postura, mais ativa que a da OEA, coincidiu com a posição adotada pelo Brasil. Os enviados desses dois países tiveram papel central na resolução da situação, dialogando e construindo acordos com Evo Morales, a COB (Central Operária Boliviana), o

82 líder sindical e presidente do Movimento Indígena Pacha Kuti, Felipe Quispe, o exército, a igreja e a embaixada dos Estados Unidos. Assim, a Bolívia estabeleceu um olhar mais regional que hemisférico da democracia e, portanto, uma escolha institucional centrada na seleção.

Essa visão se consolidou em 2005, quando novamente os protestos forçaram o presidente boliviano Carlos Mesa a apresentar sua renúncia e convocar eleições. Novamente, a OEA e a Argentina tomaram diferentes caminhos. A OEA se limitou a oferecer respostas diplomáticas por meio de uma declaração em que lamentou a situação, reconheceu os esforços de Mesa e pediu aos lideres bolivianos que resolvessem a crise democraticamente. Já a Argentina e o Brasil atenderam ao pedido de ajuda do próprio Carlos Mesa, exercendo papel-chave nesse conflito.

O caso do Equador, em 2005, quando o presidente Lucio Gutiérrez foi substituído irregularmente por seu vice-presidente, Alfredo Palácio, mostrou a Argentina 
e a OEA mais próximos que nas crises anteriores, não tanto por ter havido mudança na posição da Argentina, mas sim porque a própria OEA mostrou maior comprometimento, invocando, dessa vez, a Carta Interamericana Democrática e supervisionando a seleção dos juízes da nova Corte Suprema. O governo argentino manifestou sua preocupação pela "grave crise institucional" que atravessava o Equador. Néstor Kirchner também invocou a Carta, solicitando que, conforme seus princípios, se preservara e fortalecera a institucionalidade democrática. Nessa ocasião, a seleção beneficiou a OEA.

A partir de 2008, o Mercosul e a OEA começaram a conviver com a Unasul como outro fórum para elevar demandas democráticas na região. Em 2008, por exemplo, diante do instável panorama político que ameaçou a continuidade de Evo Morales no poder, tanto a OEA como a Unasul se mobilizaram diplomaticamente para dissuadir as forças que ameaçavam destituir o presidente. As duas organizações enviaram observadores e promoveram o diálogo. O conflito foi abordado na cúpula da Unasul, durante a qual os presidentes argentino e brasileiro afirmaram que a América do Sul havia dado um exemplo de como construir multilateralismo apesar das diferenças. Pontualmente, Kirchner sinalizou que, na Unasul, "houve unanimidade para ajudar a Bolívia na defesa da democracia e o diálogo para solucionar a crise interna", que "o exercício de multilateralidade é uma convicção das regiões emergentes", e que se aclarou "o respaldo absoluto a todos os países cujas democracias são frágeis e suas instituições necessitam do apoio internacional" (Malamud, 2008). Um elemento que fortaleceu o papel da Unasul foi a denúncia que Evo Morales fez contra os Estados Unidos, acusando-o de estar envolvido nos protestos contra seu governo.

A Unasul exerceu novamente seu protagonismo em junho de 2009, quando Manuel Zelaya, presidente de Hon- 
duras, foi expulso do país em aberta violação à democracia. A OEA condenou o golpe e invocou a Carta. A Unasul condenou o golpe, exigiu o retorno de Manuel Zelaya à presidência e não reconheceu o governo do eleito Porfirio Lobo. Honduras foi suspensa da OEA e aceita novamente em junho de 2011, um ano e meio depois de Porfirio Lobo assumir a presidência. Com o tempo, a Argentina foi se distanciando da posição da OEA, especialmente quando os Estados Unidos reconheceram o governo de Porfirio Lobo, seguido pela Colômbia e pelo Chile. O governo argentino, entretanto, concordou com as conclusões da Comissão Interamericana de Direitos Humanos, cujo informe mostrou preocupação pela contínua violação dos direitos humanos em Honduras.

A Argentina afastou-se da posição da Assembleia Geral, mas aproximou-se da Comissão. Mas Cristina Kirchner, que encabeçou a delegação da OEA em visita a Honduras, criti84 cou a organização afirmando: “O Mercosul nunca aceitará um país sem democracia, porque tem uma cláusula democrática"; no entanto, "a OEA também tem uma cláusula democrática, mas é um pouco mais elástica” (La Nación, 2009). A crítica, sem dúvida, estava dirigida aos Estados Unidos. Sendo talvez o último país da região a fazê-lo, a Argentina só restabeleceu suas relações com Honduras em janeiro de 2012. A escolha institucional argentina para o caso de Honduras mostrou, primeiro, a seleção da OEA como ponto focal, para, em seguida, marcar sua posição na Unasul.

Diante do ataque da polícia ao presidente equatoriano Rafael Correa, em 2010, a OEA expressou seu apoio ao governo, e a Unasul condenou a tentativa de golpe à ordem constitucional. A posição da Argentina foi forte em termos discursivos. O chanceler Hector Timerman afirmou que a revolta no Equador havia sido "uma ameaça para a democracia e não vamos deixar passar" e pediu 
que "as democracias da América Latina não permitam que ocorra no Equador o que ocorreu em Honduras" ( $\mathrm{La}$ Nación, 2010). Atuando como secretário-geral da Unasul, Néstor Kirchner expressou, em um comunicado, "o firme compromisso e a mais absoluta solidariedade" do bloco com Correa, afirmando ainda que "a América do Sul não pode tolerar em nenhum aspecto que os governos eleitos democraticamente se vejam pressionados e ameaçados por setores que não querem perder privilégios e favores" (Página 12, 2010). A crise equatoriana ensejou a ideia de que a Unasul deveria contar com sua própria carta democrática, ideia que ficou corporificada na Declaração de Buenos Aires, promovida pela Argentina, e no Protocolo Adicional ao Tratado da Unasul, aprovado no mesmo ano. Não houve somente uma seleção a favor da Unasul, mas também se impulsionou uma modificação para dotá-la de um instrumento mais apropriado para enfrentar crises democráticas.

O último episódio a comentar é o julgamento político do presidente do Paraguai, Fernando Lugo, promovido em junho de 2011 pela oposição e por seu vice-presidente, Federico Franco. Novamente, a Argentina e a OEA tomaram caminhos diferentes. A postura da OEA começou sendo mais dura do que finalmente foi. O Mercosul, uma semana depois da destituição de Lugo, decidiu suspender o Paraguai do bloco. A Argentina, juntamente com os demais países do bloco, enquadrou a situação no Paraguai no Protocolo de Ushuaia e no Protocolo Adicional da Unasul. Nessa ocasião, Cristina Kirchner afirmou que a Argentina não reconheceria o governo de Franco. Suas palavras foram: "O que houve no Paraguai é algo inaceitável para uma região que havia superado definitivamente esse tipo de situação antidemocrática e contrária às instituições". Quando a presidente invocou as cláusulas democráticas em seu discurso, omitiu a da OEA: "É imprescindível que as autoridades paraguaias 
obedeçam com pleno respeito às clausulas democráticas da Unasul, do Mercosul e da Celac”. Cristina ainda afirmou: "As ações em curso poderiam se compreendidas nos artigos 1, 5 e 6 do Protocolo Adicional do Tratado Construtivo da Unasul sobre o compromisso com a democracia, configurando uma ameaça de ruptura à ordem democrática” ( $L a$ Nación, 2012).

\section{Um caso de seleção}

Até a criação da Unasul, a Argentina utilizava os instrumentos da OEA. Com a criação do bloco, o país selecionou a Unasul, a OEA e o Mercosul em função do papel assumido pelos Estados Unidos e das crescentes preferências argentinas por constituir a Unasul como uma instituição focal da América do Sul para a defesa e promoção da democracia. Nesse sentido, a OEA segue a instituição focal em matéria democrática no hemisfério, mas não 86 parece exercer uma influência substantiva nas preferências da Argentina.

No que diz respeito ao âmbito doméstico, não existem atores que possam vetar esse comportamento, dentro ou fora do Estado. O que há, entretanto, são atores mais propícios a proteger a democracia como bem público regional, privilegiando o papel da Unasul mas nem tanto o da OEA. Contra a hipótese institucionalista, o motivo não tem relação com a efetividade de uma e de outras, mas sim com a maior margem de manobra que existe ao não estarem presentes nos Estados Unidos.

\section{0 regime interamericano de direitos humanos e a escolha institucional da Argentina}

Diferentemente do regime de segurança, o regime interamericano dos direitos humanos não responde a uma oferta hegemônica dos Estados Unidos, mas, sim, a uma demanda coletiva dos Estados da América do Sul. De fato, 
até agora, os Estados Unidos não ratificaram nenhum tratado regional de direitos humanos. Apesar disso, o regime de direitos humanos é o mais institucionalizado dos três, e um ponto focal por excelência, para tratar dos casos de violação, seja através da Comissão Interamericana de Direitos Humanos, seja da Corte Interamericana de Direitos Humanos. O impacto de ambos os órgãos foi notável, incluindo visitas e denúncias em períodos de ditadura; revogação de leis de desacato; aprovação de leis de acesso à informação; reforma da justiça militar e de entrega de terras a indígenas, entre outros. Existem, porém, distintos tipos de "usuários" do sistema, de acordo com a proteção aceita por cada Estado ${ }^{7}$.

A institucionalização desse regime não só se viu favorecida pela convergência das preferências dos Estados da região, como também pela ativa ação de uma ampla rede de atores sociais interessados em aprofundar o papel da Comissão e da Corte. Em um estudo quantitativo sobre a efetividade do Sistema Interamericano de Direitos Humanos (SIDH), Basch e colaboradores verificaram que, entre 2001 e 2006, em 34\% dos casos, houve demanda por uma organização não governamental nacional, e, em 30\%, demanda por uma combinação de, ao menos, uma ONG internacional e uma ONG nacional; finalmente, em 12\% dos casos, houve demanda por uma ONG internacional (Basch et al., 2010, p.26).

Ainda que haja muitas discussões em torno do estado e do futuro do regime (Dulitzky, 2011), é correto afirmar que, em termos relativos, o regime interamericano goza de

\footnotetext{
${ }^{7}$ Há cidadãos que podem ter acesso ao amparo judicial porque seus Estados ratificaram a Convenção e reconheceram a Corte. Há também aqueles que podem ter acesso ao amparo quase judicial porque seus Estados ratificaram a Convenção, mas não reconheceram a Corte. Finalmente, há aqueles cidadãos que apenas podem ter acesso a um amparo declarativo judicial porque seus Estados não ratificaram a Convenção, nem aceitaram o papel da Corte.
} 
legitimidade, é o mais autônomo dos três e sua legalização está aumentando. Dito isso, há que dar conta da existência de um conjunto de Estados que criticam o regime. Estes, representados por Bolívia, Equador, Venezuela e Nicarágua, desejariam modificar substantivamente o regime. A expressão mais acabada veio de Evo Morales quando, em 2012, manifestou que a Comissão tinha duas opções: "ou morre como um servente do império ou revive para servir a todas as nações da América” (Rivera Juaristi, 2012, p.19). Mesmo que essa discussão tenha ocorrido no centro da Comissão, durante 2012, até meados de 2013, a posição final que acabou prevalecendo foi a da maioria, que defende a Comissão para aumentar sua efetividade.

A centralidade da Comissão e sua contestação por parte da Bolívia, do Equador e da Venezuela talvez explique por que a Unasul carece de um Conselho de Direitos Humanos. Diferentemente da Unasul, o Mercosul vem dando poucos, 88 mas importantes, passos em matéria de direitos humanos. A instância máxima acerca de direitos humanos no Mercosul é a Reunião de Altas Autoridades em Direitos Humanos. Essa instância delegou ao Instituto de Políticas Públicas de Direitos Humanos do Mercosul o desenho e a implantação das políticas em direitos humanos. Em 2012, os quatro membros plenos do Mercosul solicitaram uma opinião consultiva da Corte Interamericana de Direitos Humanos sobre a migração de crianças. É a primeira vez na história do regime que vários Estados realizam um pedido em conjunto. O Instituto de Políticas Públicas de Direitos Humanos do Mercosul teve um papel central nos detalhes técnicos para articular o pedido dos quatro países.

Mesmo que o usuário por excelência do regime de direitos humanos não seja o Estado (ou mesmo que possa ser), se não são os cidadãos, são os governos que defendem as práticas e normas centrais do regime, em particular suas regras de ação e a possibilidade de delegar novas funções 
ou procedimentos. Nesse sentido, o apoio da Argentina à Comissão e à Corte tem sido notável. Primeiro, as preferências argentinas ao regime estão ancoradas constitucionalmente, já que o país ratificou a Convenção e aceitou o papel da Corte. Segundo, a Argentina colabora com diferentes iniciativas da Comissão, como a abertura, em 2011, dos arquivos de denúncias recebidas pela OEA, processo impulsionado pelo então secretário executivo da Comissão, o argentino Santiago Cantón. Outro exemplo é a participação argentina na conformação de um Grupo de Trabalho (AG/RES 2.372, de 2010) para fazer a revisão das normas sobre desastres naturais e assistência humanitária. Terceiro, a Argentina teve um papel construtivo nos debates ocorridos entre 2012 e 2013 pelo futuro da Comissão, atuando como moderador entre posições difíceis de conciliar. Em síntese, como expressou o então chanceler Jorge Taiana (2009), para a Argentina o regime cumpriu "um papel de enorme importância nas Américas, tanto no marco da luta pela recuperação do estado de direito como na atualidade, como mecanismo de alerta e de melhoramento institucional a partir da resolução de casos individuais". Taiana afirmou que a visita da Comissão em 1979 foi "um marco para a recuperação da democracia na Argentina" e se referiu aos "esforços realizados nos Estados da região para fortalecer o sistema interamericano de proteção dos direitos humanos, ao qual tanto devem as sociedades latino-americanas que padeceram a crueldade das ditaduras militares".

A segunda preferência que surge na política exterior argentina consiste em investir institucionalmente no Mercosul em matéria de direitos humanos. Isso pode ser observado, como visto acima, na criação da Reunião de Altas Autoridades e do Instituto. A Argentina desempenhou papel central na criação dessa agência especializada, e seu secretário executivo, o argentino Victor Abramovich, foi diretor executivo do Centro de Estudos Legais e Sociais (CELS) e 
membro da Comissão Interamericana de Direitos Humanos da OEA. Cabe assinalar que a sede do Instituto é a única de um órgão permanente do Mercosul que não está em Montevidéu, mas sim em Buenos Aires. Cabe ressaltar, também, que, desde o início de seu funcionamento, em 2010, até o reconhecimento de seu status jurídico, em 2012, a totalidade de seu orçamento esteve a cargo do governo argentino, executado através da Secretaria de Direitos Humanos.

A criação institucional do Instituto de Direitos Humanos do Mercosul, neste caso, não deveria ser considerada uma escolha institucional oposta ao uso do regime interamericano. A evidência sugere, pelo contrário, que essa escolha institucional está em sintonia com o uso do regime da OEA, por isso o instituto não seria uma barreira, mas uma ponte normativa entre a OEA e o Mercosul, sendo outro ator, porém fazendo uso do regime interamericano.

$\mathrm{Na}$ base dessas preferências encontra-se uma união de 90 atores públicos e privados com extensos laços, históricos e presentes, com Comissão e a Corte. Algumas organizações da sociedade civil, notadamente o Centro de Estudos Legais e Sociais, não só monitoraram e denunciaram politicamente a violação de direitos humanos, como também peticionaram diante da Comissão. Assim ocorreu em 2011, quando o CELS e a Comissão Bonaerense pela Memória apresentaram ante a Comissão imagens da Unidade Penal 48 e um diagnóstico extremamente crítico das condições de detenção dos presos. Nesta, e em outras ocasiões, Horacio Verbitsky amparou suas críticas ao sistema carcerário e policial em pronunciamentos da CIDH e da Corte.

\section{Um caso do uso institucional}

O regime internacional como ponto focal e a união doméstica de preferências favoráveis ao regime têm sido os determinantes do uso institucional do regime. Essas preferências se mantiveram inclusive nos momentos, como o atual, em 
que a Comissão tem sido submetida a pressões pelos países próximos à Argentina, como Bolívia, Equador e Venezuela. Ademais, o regime não foi uma oferta feita pelo ator hegemônico, os Estados Unidos; o papel desse país nesse espaço tem sido menos visível que nos temas de defesa, segurança e democracia. Assim, a política exterior argentina se explica menos pela distribuição de poder e mais pela institucionalização e pelas preferências domésticas. A chancelaria (em particular durante os anos de Jorge Taiana, ex-secretário executivo da CIDH), o CELS, o Instituto de Direitos Humanos do Mercosul, a Secretaria de Direitos Humanos e outras organizações não governamentais têm oferecido uma sólida rede de especialistas, ativistas e demandantes que percebem como positivo seguir utilizando a OEA.

\section{Considerações finais}

A escolha institucional da Argentina no plano de defesa e segurança situa-se em torno da modificação (da OEA) e da criação (do CSD) institucional. A escolha institucional no plano da democracia situa-se na seleção institucional, optando ora pela OEA, ora pelo Mercosul e pela Unasul. No entanto, a escolha institucional em matéria de direitos humanos, situa-se no uso da OEA. Como se explica essa variação na escolha institucional? No plano da defesa e da segurança, o papel desempenhado pelos Estados Unidos, a perda da centralidade do regime e as preferências argentinas por cooperar mais no eixo sul-americano que em nível hemisférico levam a Argentina a modificar o status quo e construir algo novo. Nesse sentido, o poder e as preferências domésticas explicam boa parte da escolha institucional do país. Dito de outro modo, a Argentina vê como negativa a influência dos Estados Unidos nesse assunto. Percebe, também, que a ausência de uma instituição focal hemisférica reduz os custos de não cooperar nessa região. Finalmente, os atores domésticos preferem construir acordos de coo- 
peração na América do Sul, como o espaço mais relevante para a defesa e segurança do país.

Em matéria de promoção e defesa da democracia, a existência de um ponto focal hemisférico (a Carta Democrática da OEA) e a preferência argentina pela democracia leva a cooperar com o regime. A influência projetada pelos Estados Unidos, no entanto, a distância do regime, e, portanto, sua escolha institucional estão em um ponto médio, a seleção institucional. Desse modo, tanto o poder como as instituições influenciam nas preferências, mesmo que em direções opostas. A Argentina percebe como negativa a influência dos Estados Unidos no regime democrático, entretanto, percebe que a presença de uma instituição focal hemisférica, criada com sua contribuição, eleva os custos de não cooperar e pode prejudicar a reputação do país. Finalmente, a ausência de veto players em um sentido (contra a OEA), ou outro (contra a Unasul) conduz a uma escolha 92 intermediária, que consiste em escolher o marco normativo de acordo as circunstâncias.

Por último, em matéria de direitos humanos, a menor presença dos Estados Unidos, a presença de uma instituição focal hemisférica (Comissão e Corte) e as preferências domésticas levam a Argentina a escolher o uso da OEA.

Ao menos, o caso argentino revela que a escolha institucional está sensivelmente influenciada pelas preferências domésticas. Esta observação, que parece extremamente óbvia, sugere, entretanto, que os Estados não necessariamente fazem o que podem em função da distribuição de poder (como afirma o realismo), nem o que sabem em função da distribuição da informação (como afirma o institucionalismo), apenas o que querem em função da distribuição de preferências (como afirma a teoria de formação doméstica das preferências). Como sustenta Andrew Moravcsik (1997, p.522), a variação nos fins, não nos meios, importa mais. 
Sustentar que as preferências dão forma à escolha institucional não significa eliminar a importância das variáveis sistêmicas, como o poder e as instituições. As preferências estão em interdependência com as preferências de outros Estados e a interação estratégica entre elas opera em um contexto material e institucional específico. Assim, eles podem levar a política exterior em uma direção, mas, se as restrições externas materiais e institucionais são altas, é de esperar que essas preferências sejam moderadas ou neutralizadas pelo contexto. Mas se as preferências se formam em um contexto de poucas restrições materiais e institucionais, provavelmente serão a fonte de política exterior.

Assim, deduz-se que o debate pela supremacia de uma fonte sobre outra não deveria ser ontológico e, sim, mais empírico. Em contextos altamente institucionalizados ou com restrições materiais substantivas, é mais provável que as fontes externas deem forma à política exterior. No entanto, em contextos de baixa institucionalização e de ausência de restrições materiais, as preferências domésticas exerceriam maior influência sobre o comportamento do Estado. Tipicamente, os realistas e os institucionalistas mantêm constante a política doméstica, para, em seguida, ver como as mudanças no sistema afetam o comportamento das unidades. Os liberais, por outra parte, teorizam sobre o âmbito doméstico e mantêm constante o nível sistêmico. Assumem a continuidade do espaço internacional e analisam de que modo as variações internas afetam a política exterior dos Estados (Gourevitch, 2006). Como mostra o caso argentino no contexto hemisférico, quando a variação ocorre tanto no nível sistêmico como no doméstico, resulta imprescindível examinar a interação entre ambos os níveis para compreender de modo mais preciso a escolha institucional. 


\section{Federico Merke}

é professor de relações internacionais na Universidad de San Andrés e pesquisador do Conicet, Argentina.

\section{Referências bibliográficas}

ARGENTINA. 2012. Aportes de la República Argentina para la reunión de debate sobre el futuro de la misión y funciones de los instrumentos y componentes del Sistema Interamericano de Defensa. Organización de los Estados Americanos, Comisión de Seguridad Hemisférica, CP/CSH-1478/13, 8 mar.

BASCH, F. et al. 2010. "A eficácia do Sistema Interamericano de Proteção de Direitos Humanos: uma abordagem quantitativa sobre seu funcionamento e sobre o cumprimento de suas decisões". Sur - Revista Interncional de Direitos Humanos, v.7, n.12, p. 9-35.

DULIZKY, A. 2011. "The Inter-American Human Rights Systen fifty year later: time for changes”. Quebec Journal of International Law, special edition.

FORTI, A. 2012. "El objetivo de buscar coherencia a nivel continental". Tiempo Argentino, 8 abr. Disponível em: <http:/ / tiempo.infonews. com/2012/04/08/editorial-72560-el-objetivo-de-buscar-coherencia-a-

GOUREVITCH, P. 2006. "Domestic politics and international relations". In: CARLNAESS, W. et al. (eds.). Handbook of international relations. London: Sage.

HOFMANN, S. C.; MÉRAND, F. 2012. "Regional Organizations à la carte: the effects of institutional elasticity". In: PAUL, T. V. (ed.). International relations theory and regional transformation. Cambridge: Cambridge University Press.

KATZENSTEIN, P.; SIL, R. 2010 Beyond paradigms: analytic eclecticism in the study of world politics. New York: Palgrave Macmillan.

KEOHANE, R. 1993. Instituciones internacionales y poder estatal. Buenos Aires: GEL.

JUPILLE, J.; SNIDAL, D. 2005. The choice of international institutions: cooperation, alternatives and strategies. Mimeo.

LA NACIÓN. 2009. "Tras una fuerte discusión, el bloque condenó a Honduras". 9 dez. Disponível em: <http:/ /www.lanacion.com. ar/1209410-tras-una-fuerte-discusion-el-bloque-condeno-a-honduras $>$.

LA NACIÓN. 2010. "Comenzó la reunión de emergencia de la Unasur". 1 out. Disponível em: <http://www.lanacion.com.ar/1309820comenzo-la-reunion-de-emergencia-de-la-unasur> 
LA NACIÓN. 2012. “Argentina 'no convalidará el golpe en Paraguay' mientras que Brasil sugirió que quedaría fuera de la Unasur y el Mercosur". 23 jun. Disponível em: <http://www.lanacion.com. ar/1484357-unasur-y-mercosur-tomaria-medidas-severas-ante-laremocion-de-lugo $>$.

MALAMUD, C. 2008. "La Cumbre de Unasur en Santiago de Chile y el conflicto en Bolivia”. ARI 121, Madrid, Real Instituto Elcano.

MEARSHEIMER, J. J. 1994-95. "The false promise of international institucions”. International Security, v.19, n.3, pp.5-49.

MORAVCSIK, A. 1997. "Taking preferences seriously: a liberal theory of international politics”. International Organization, v.51, n.4, pp.513-53.

PÁGINA 12. 2010. "Todo el arco político repudió la sublevación policial”. 30 set. Disponível em: <http://www.pagina12.com.ar/diario/ ultimas/20-154099-2010-09-30.html>.

RAMÍREZ, L. 2011. "Principales instrumentos jurídicos que resguardan la democracia en las Américas”. Américas, v.63, n.4. Disponível em: <http://www.oas.org/es/americas/article.asp?df_sCodigo=6368>.

RIVERA JUARISTI, F. 2012. "U.S. Exceptionalism and the strengthening process of the Inter-American Human Rights System”. Human Rights Brief, v.20, n.2, pp.19-25.

TAIANA, J. E. 2009. "La visita de 1979 inició el fin de la impunidad”.

Disponível em: <http://prensa.cancilleria.gov.ar/noticia. php?id=18707873>.

VERBISTKY, H. 2012. "Las cartas sobre la mesa”. Página 12, 30 set. Disponível em: <http://www.pagina12.com.ar/diario/ elpais/1-204541-2012-09-30.html>. 


\section{POLÍTICA EXTERIOR DA ARGENTINA E ESCOLHA INSTITUCIONAL: A OEA NO ESPELHO DA UNASUL E DO MERCOSUL}

\section{FEDERICO MERKE}

Resumo: Desde 1983, a Argentina adotou um perfil elevado na provisão de três bens públicos regionais: segurança interestatal, democracia e direitos humanos. No entanto, a Argentina fez diversas escolhas institucionais, entre a OEA, a Unasul e o Mercosul, dependendo do bem público em questão. O país vem contribuindo com a criação institucional para cooperar com a segurança, a seleção institucional para promover a democracia e o uso institucional para promover os direitos humanos. Que fatores explicariam essa variação na escolha institucional da Argentina? Este trabalho examina as escolhas institucionais do país para a provisão de três bens públicos regionais: segurança interestatal, democracia e direitos humanos. O estudo se concentra na escolha institucional recente (de 2003 em diante) e a contrasta com o passado imediato (anos 1990) e o mais distante (desde a criação da OEA), para identificar as mudanças e continuidades.

Palavras-chave: Argentina; Política Exterior; Investimento Institucional; OEA; Unasul; Mercosul.

\section{ARGENTINA'S FOREIGN POLICY AND INSTITUTIONAL CHOICE: THE OAS IN THE MIRROR OF UNASUR AND MERCOSUR}

Abstract: Since 1983, Argentina adopted a high profile in the provision of three regional public goods: interstate security, democracy and human rights. However, Argentina has made different institutional choices, between the OAS, Unasur and Mercosur, depending on the public good in question. Argentina has therefore contributed to the institutional creation to cooperate in the security are; has practiced institutional selection to promote 
democracy and has made institutional use to promote human rights. What factors explain this variation in the institutional choice of Argentina? This paper examines Argentina's institutional choices for the provision of three regional public goods, namely interstate security, democracy and human rights. The study focuses on recent institutional choice (from 2003 onwards) and contrasts with the immediate past (the decade of the 1990s) and longest (since the creation of the OAS), to identify changes and continuities in Argentina's institutional choices.

Keywords: Argentina; Foreign Policy; Institutional Investment; OAS; Unasur, Mercosur.

Recebido: 02/05/2013 Aprovado: 15/08/2013 